\title{
Carvalhos, juncos, árvores e rizomas: paradigmas na formação de professores
}

\section{Oaks reeds, trees and rhizomes: paradigms in teacher education}

\author{
Clarissa Menezes Jordão* \\ Universidade Federal do Paraná \\ Curitiba - Paraná / Brasil \\ Francisco Carlos Fogaça** \\ Universidade Federal do Paraná \\ Curitiba - Paraná / Brasil
}

\begin{abstract}
RESUMO: Este artigo tem por objetivo discutir, a partir da análise de dados empíricos, as metáforas do mundo enquanto rizoma e enquanto árvore, tal como apresentadas por Deleuze e Guattari (1995), relacionando-as à formação inicial e continuada de professores de línguas estrangeiras. Para tanto, analisamos uma atividade realizada durante um curso de formação de professores de inglês "em serviço", na qual os participantes tiveram como tarefa representar o seu desenvolvimento profissional por meio do desenho de uma árvore. A análise interpretativa situa essas representações em relação aos paradigmas arbóreo e rizomático, assim como problematiza a própria perspectiva adotada na proposição da atividade. Embora os desenhos tivessem uma clara relação com a metáfora da árvore, uma vez que a tarefa em si induzia a isso, pudemos também encontrar referências à metáfora do rizoma, o que nos levou a considerar que a perspectiva rizomática encontra espaço mesmo em meio à rigidez disciplinar da formação, desestabilizando e transformando processos identitários no desenvolvimento profissional.
\end{abstract}

PALAVRAS-CHAVE: formação de professores; rizoma; paradigma; desenvolvimento profissional.

ABSTRACT: This paper aims at promoting a discussion of the rhizome versus tree metaphor as presented by Deleuze and Guattari (1995; 2009), relating such metaphor to the field of foreign language teacher education. In order to do so, we analyse a task presented to the participants of an in-service EFL teacher education course: the task required the teachers to represent their professional development

\footnotetext{
* clarissamjordao@gmail.com

** fcfogaca@gmail.com
} 
by drawing a tree that would signify the different stages of such development. Our interpretive analysis examines not only the drawings produced by the teachers, but also the task itself in their relation to the rhizome and tree metaphor. Although the drawings showed obvious traces of the tree metaphor, if only because the task itself required that, we could also find references to the rhizome metaphor, what allowed us to conclude that the rhizome perspective finds its way even within academic disciplinary rigidity, thus destabilizing and transforming identity processes in professional development.

KEYWORDS: teacher education; paradigm; rhizome; professional development.

Lá no horizonte furiosamente surgiu

A mais terrível das tempestades

Que os ventos do norte podiam trazer.

A árvore tentou resistir, o junco se curvou.

$\mathrm{O}$ vento redobrou seus esforços.

E tanto fez que destruiu

Aquele que tinha o céu como vizinho de cima

$\mathrm{E}$ as raízes no andar de baixo.

Jean de La Fontaine ${ }^{1}$

A epígrafe acima é parte da fábula "O carvalho e o junco", escrita pelo poeta e fabulista francês Jean de La Fontaine (1621-1695). Nessa fábula, um frondoso carvalho vangloria-se de seu porte e estrutura resistente, desdenhando de um pequeno junco, de aparência delgada e frágil. A enorme árvore, vaidosa e prepotente, oferece seus galhos robustos e sua copa abrangente como abrigo à delicada plantinha. Em breve chega uma furiosa tempestade, com ventos poderosíssimos que acabam por derrubar a imponente árvore, expondo suas raízes; o junco, por sua vez, mais flexível e adaptável a situações adversas, dobra-se diante dos ventos, mas permanece intacto. $\mathrm{O}$ carvalho, que tinha como vizinho de cima o céu e suas raízes no andar de baixo, encerra seu ciclo de vida, desabando com toda a sua estrutura.

A árvore, personificada nesta fábula por meio do vaidoso carvalho, e certamente um dos mais conhecidos símbolos da vida, presente em inúmeras metáforas relacionadas à existência humana, também simboliza o que Deleuze e Guattari (1995) chamam de "cultura arborescente", em oposição à metáfora do rizoma, conceitos tratados neste texto como paradigmas arbóreo $e$ rizomático.

${ }^{1}$ A fábula completa se encontra no Anexo A. 
O objetivo geral deste artigo é apresentar e discutir tais paradigmas em relação à formação inicial e continuada de professores de línguas estrangeiras, juntamente com uma análise de dados empíricos realizada de forma interpretativa e trazida aqui como uma oportunidade de ilustração desses dois paradigmas. Para tanto, realizamos uma pesquisa junto aos professores de língua inglesa do CELIN (Centro de Línguas e Interculturalidade da UFPR). ${ }^{2}$ Os professores, em sua grande maioria alunos ou ex-alunos da UFPR, participavam de um encontro pedagógico realizado em agosto de 2008, e tiveram como tarefa desenhar uma árvore que representasse seu desenvolvimento profissional (ver Anexo B). ${ }^{3}$ Dos 25 professores da área de inglês da instituição, 18 participaram do encontro e fizeram o desenho solicitado, explicando e discutindo posteriormente com o grupo suas intençôes no processo de representação visual de seu desenvolvimento profissional. As representações dos participantes, registradas em seus desenhos, foram analisadas de forma interpretativa em relação aos paradigmas arbóreo e rizomático, conforme se ajustassem ou distanciassem de um ou de outro. No processo de análise, assumimos nossa subjetividade e a responsabilidade pelas interpretações feitas. A análise aqui apresentada não segue os padrões usuais com o estabelecimento de quadros de referência ou de categorias prévias a partir das quais os dados são gerados; seguimos os procedimentos da etnografia pós-moderna como sugeridos por Clifford (1986) em sua proposta de "alegoria etnográfica", respeitando a natureza dos dados sem diferenciar "interpretação" de "análise"

${ }^{2}$ Conforme informações contidas no website da instituição (www.celin.ufpr.br), "o Centro de Línguas e Interculturalidade tem por objetivo "oferecer aos alunos e professores de graduação e pós-graduação em Letras um espaço para desenvolver pesquisas na área de ensino de línguas e culturas diversas e observação e reflexão sobre a prática pedagógica". O CELIN atua como um espaço de formação de professores, dando oportunidade aos alunos de graduação de ter alguma prática pedagógica durante o curso. Além disso, por meio de reuniōes pedagógicas e encontros de professores, os alunos-professores têm a possibilidade de trabalhar colaborativamente na preparação de aulas e na discussão de temas relevantes para a sua formação. Outro de seus objetivos "é a promoção de cursos de línguas que representam etnias formadoras da nossa comunidade (polonês, ucraniano, hebraico, japonês, russo, chinês, guarani, árabe, dentre outras), de línguas mercadológicas, assim como cursos de línguas relevantes para a formação profissional da população curitibana, a saber: alemão, espanhol, francês, inglês e italiano".

${ }^{3} \mathrm{O}$ Anexo B é um exemplo de desenho feito por um dos professores (P11). 
- sob o pressuposto de que, se os sentidos são construídos no discurso (e não antes ou fora dele), ao analisarmos, estamos sempre interpretando.

$\mathrm{Na}$ época da pesquisa, atuávamos na equipe da coordenação pedagógica da área de inglês da instituição. Entre as funções que realizávamos, estavam: organizar encontros e reuniões pedagógicas mensais e semestrais; organizar encontros semanais entre os membros da coordenação pedagógica (um coordenador e quatro assessores); observar aulas dos alunos-professores e orientá-los; coordenar projetos de aprendizagem colaborativa; promover palestras por meio de professores convidados e membros da equipe; entre outras atividades.

\section{O paradigma arbóreo e o ciclo de vida profissional dos professores}

A “metáfora da árvore” tem sido utilizada em diversos contextos, geralmente com ênfase na ideia de que árvores possuem uma estrutura sólida, partindo de um único tronco, mas que se ramifica nas extremidades. É assim, por exemplo, na metáfora da "árvore genealógica”, que constitui um histórico de certa parte dos ancestrais de uma família ou indivíduo, partindo sempre de um tronco familiar. Uma árvore genealógica representa graficamente as conexôes familiares, trazendo seus nomes, datas, lugares de nascimento, casamento e falecimento, mostrando as ramificaçóes dos indivíduos como se fossem as de uma árvore. Temos também, por meio dessa representação, a ideia de que a vida se dá em ciclos regulares, do nascimento à morte.

Outra metáfora é a da "árvore da vida", ou "árvore do conhecimento" do bem e do mal, colocada por Deus, conforme o relato bíblico, no Jardim do Éden antes da criação dos seres humanos. Tal árvore seria a garantia de uma vida eterna para aqueles a quem Deus permitisse comer de seus frutos. Quando Adão desobedeceu às ordens do criador e comeu o fruto da árvore (a maçã) antes que tal permissão lhe fosse dada, perdeu a oportunidade de que ele e sua descendência alcançassem a vida eterna. Aqui também vemos a árvore como o símbolo da vida, do desenvolvimento humano, ligada à ideia de solidez e longevidade.

Da mesma forma, a "metáfora da semente" que germina em terra fértil, se desenvolve e dá bons frutos é usada para ilustrar o ciclo positivo da vida, das ações que frutificam. A semente já contém potencialmente propriedades para se desenvolver e se transformar em árvore, dando início ao ciclo da vida, "a reprodução miniaturizada do organismo fadado a crescer” (DINES, 2004, [n.p.]). ${ }^{4}$

${ }^{4}<$ http://www.observatoriodaimprensa.com.br/artigos.asp?.cod=275OI8005>. 
Ainda dentro da ideia "arbórea" da vida em ciclos, diversos autores (FEIMAN-NEMSER [1982]; HUBERMAN [1995]; WOODWARD [2000]; FOLLE et al. [2008], entre outros) estudaram os ciclos de desenvolvimento profissional na carreira do professor e identificaram algumas etapas relacionadas à motivação. Com base em questionários e entrevistas, Huberman estudou esses ciclos no desenvolvimento de 160 professores do Ensino Médio na Suíça, os quais compreendem as seguintes etapas: a) fase de um a três anos, chamada de entrada na carreira. Tal etapa envolve o aprendizado básico para sobreviver na profissão, e também um choque com as dificuldades iniciais; b) fase de quatro a seis anos, chamada de estabilização. Essa etapa envolve assumir responsabilidades, fazer escolhas profissionais e traçar objetivos; c) na fase da diversificação (ou ativismo), de sete a 18 anos, o professor tem o desejo de utilizar materiais e recursos diferentes, novas formas de organizar os alunos em sala de aula e os conteúdos ensinados, além de buscar mudanças institucionais; é uma época de autoavaliação e de questionamentos mais intensos, de idealismo. Os professores nessa fase seriam os mais motivados e dinâmicos, empenhados em participar de comissōes de reforma e equipes pedagógicas. Nessa fase, alguns professores questionam a sua carreira, correspondendo ao que Huberman chama de "fases arquetípicas" da vida (HUBERMAN, 1995, p. 43), nas quais as pessoas examinam o que fizeram em suas vidas em relação aos objetivos que tinham inicialmente; alguns encaram a ideia de continuar na carreira, mas outros se mostram inseguros e decidem seguir outro percurso; d) de 19 a 30 anos, a fase da serenidade envolve a aceitação das limitaçōes da atividade profissional e de certas idiossincrasias; o professor se vê e se aceita como um veterano, com experiência acumulada, e que tem erros e acertos. Alguns professores, no entanto, apresentam uma atitude de maior resistência a inovaçôes e certo saudosismo em relação ao passado, numa postura mais conservadora e queixosa em relação aos alunos, aos colegas de profissão, à política educacional e ao ensino em geral; e) na etapa do desinvestimento, o professor dá início a uma fase de menor empenho no seu trabalho, tornando-se mais sereno e reflexivo; poderá sentir-se realizado com o seu desempenho profissional ao longo dos anos, ou desencantado e amargo, se o balanço for negativo. Esse período "enceta um processo de desinvestimento nos planos pessoal e institucional, um recuo face às ambições aos ideais presentes à partida" (HUBERMAN, 1995, p. 46).

Tais fases parecem ocorrer de maneira genérica na vida de um grande número de professores, mas não necessariamente se aplicam a todos eles, tampouco se desenvolvem de forma linear, ou seja, alguns professores podem 
passar por algumas dessas etapas, mas não nessa ordem e não por todas elas. Nas palavras de Huberman, "há pessoas que 'estabilizam' cedo, outras o fazem mais tarde, outras não o fazem nunca e outras ainda que estabilizam, para desestabilizar de seguida" (HUBERMAN, 1995, p. 39).

Essa perspectiva cíclica no desenvolvimento profissional de professores parece estar relacionada à metáfora da árvore, uma vez que pressupõe a ideia de nascimento (início da carreira), desenvolvimento (fase produtiva e idealista) e morte (período de acomodação e desinteresse). Essa é a noção que temos a respeito da vida em geral, do ciclo natural ao qual todos os seres vivos estão submetidos.

A metáfora da árvore se encontra em um paradigma que podemos chamar de paradigma arbóreo. A "cultura arborescente", entendida como aquela que se pauta pela metáfora da árvore, está enraizada no pensamento ocidental, a tal ponto que ciências como a Biologia, a Psicanálise e a Linguística estão fundadas sobre ela (DELEUZE; GUATTARI, 1995, p. 23). Isso significa dizer que nosso pensamento, nossos desejos, nossas visões de mundo no Ocidente (entendido como categoria de pensamento, portanto não geográfica) se pautam por tal paradigma, ou seja, pela vontade de solidez, de segurança, de coerência, enfim, de ideias que metaforicamente nossas culturas relacionam à imagem da árvore.

Para Deleuze e Guattari, o pensamento arborescente necessita de uma unidade principal, que conecta duas ou mais partes, passando do "Uno a três, quatro ou cinco, mas sempre com a condição de dispor de uma forte unidade principal, a do pivô, que suporta as raízes secundárias" (DELEUZE; GUATTARI, 1995, p. 13). Os autores entendem que tal concepção não compreende a ideia de multiplicidade, uma vez que opera com uma lógica binária ou com relações biunívocas, partindo sempre de uma unidade comum, que lhes dá suporte. As multiplicidades são "só fingidas", não ocorrem de fato.

A árvore ou a raiz inspiram uma triste imagem do pensamento que não pára de imitar o múltiplo a partir de uma unidade superior, de centro ou de segmento. Com efeito, se se considera o conjunto galhos-raízes, o tronco desempenha o papel de segmento oposto para um dos subconjuntos percorridos de baixo para cima: um tal segmento será um "dipolo de ligação", diferentemente dos "dipolos-unidades" que formam os raios que emana de um único centro. Mas as próprias ligações podem proliferar como no sistema radícula, permanecendo no Um-Dois e nas multiplicidades só fingidas (DELEUZE; GUATTARI, 1995, p. 26). 
Conforme Deleuze e Guattari, “os sistemas arborescentes são sistemas hierárquicos que comportam centros de significância e de subjetivação, autômatos centrais como memórias organizadas" (DELEUZE; GUATTARI, 1995 , p. 26). Isso faz com que os elementos só recebam informações de unidades hierarquicamente superiores "e uma atribuição subjetiva de ligações preestabelecidas” (DELEUZE; GUATTARI, 1995, p. 26).

O pressuposto da cultura arborescente é o da organização estrutural (estruturalismo), que implica hierarquias, as ideias de início, meio e fim e de causa e efeito (SOUZA, 2011). No caso do desenvolvimento profissional do professor, a metáfora da árvore sugere que possamos pensar em etapas que se sucedem mais ou menos de forma homogênea e linear, uma conduzindo à outra - mesmo que não seja da mesma forma, com todos os indivíduos, carregará sempre a ideia de uma estrutura organizadora. Quando o desenvolvimento se completa, dá-se início a uma fase de declínio, na qual o centro de energia (unidade principal) interrompe as divisóes biunívocas ou dicotômicas e o ser começa a morrer tanto biológica como profissionalmente. Há uma ideia de fatalidade programada enraizada nesse pensamento.

\section{O paradigma rizomático}

O paradigma rizomático opera segundo outra lógica. A noção de ciclo evolutivo linear, genealógico e estrutural (presente na cultura arborescente) dá lugar ao desenvolvimento imprevisível, flexível, não hierárquico. Nas palavras de Deleuze e Guattari, "evoluímos e morremos devido a nossas gripes polimórficas e rizomáticas mais do que devido a nossas doenças de descendência ou que têm elas mesmas sua descendência" (DELEUZE; GUATTARI, 1995, p. 20). O rizoma, os autores acrescentam, "é uma antigenealogia", sem princípio e sem fim, mas sempre no meio das coisas, intermediando e construindo relaçôes.

Um rizoma não começa nem conclui, ele se encontra sempre no meio, entre as coisas, inter-ser, intermezzo. A árvore é filiação, mas o rizoma é aliança, unicamente aliança. A árvore impõe o verbo "ser", mas o rizoma tem como tecido a conjunção "e... e... e...”. Há nesta conjunção força suficiente para sacudir e desenraizar o verbo ser. Para onde vai você? De onde você vem? Aonde quer chegar? São questões inúteis (DELEUZE; GUATTARI, 1995, p. 37). 
No livro Mil platôs, os autores apontam alguns princípios que regem o paradigma do rizoma, cujo entendimento depende da reconceitualização do que se entende por realidade e conhecimento. Primeiramente, a ideia do rizoma está baseada nos princípios de conexão e heterogeneidade: ao mesmo tempo que todo e qualquer ponto de uma estrutura rizomática pode (e deve, enfatizam os autores) ser conectado a qualquer outro ponto na mesma estrutura, cada ponto mantém sua diferença em relação a todos os outros - diferença constitutiva, porque determinante da existência do ponto propriamente dita, e também construída, porque fundamental para que o ponto seja identificado como tal.

Pode ser útil aqui estabelecermos uma relação com a diferenciação que Homi Bhabha realiza entre os conceitos de diversidade e diferença: para Bhabha, assim como talvez pudéssemos dizer para o rizoma de Deleuze e Guattari, diversidade é "um objeto epistemológico", constitutivo, enquanto diferença é um "processo de enunciação da cultura como 'conhecível" (BHABHA, 1998, p. 63), construído pelo enunciar. Com esSa analogia, uma estrutura rizomática traria entre seus elementos relações de diversidade e diferença, conexōes e heterogeneidade, semelhanças e diferenças.

Relacionado a esses dois princípios, Deleuze e Guattari (1995) apontam o princípio da multiplicidade, também constitutivo do rizoma. Para eles, não existe uma individualidade central, que funcionaria como pivô para o crescimento de ramos, como no conceito mais comum de um múltiplo cujas ramificações teriam origem em uma unidade central. No rizoma, a relação metafórica estaria mais próxima da imagem das fibras nervosas que formam uma trama neuronal, que "muda necessariamente de natureza à medida que ela aumenta suas conexôes" (DELEUZE; GUATTARI, 1995, p. 17).

O quarto princípio destacado por Deleuze e Guattari é o "princípio de ruptura a-significante" (DELEUZE; GUATTARI, 1995, p. 18), segundo o qual uma estrutura rizomática resiste às quebras que a ela se imponham, retomando uma estrutura assim que ela é quebrada, mas nunca retoma a mesma estrutura, pois a quebra já a modificou. A metáfora dos filósofos para esse princípio é a de uma correição de formigas, que sempre se reconstitui montando nova estrutura. É assim que

todo rizoma compreende linhas de segmentaridade segundo as quais ele é estratificado, territorializado, organizado, significado, atribuído, etc.; mas compreende também linhas de desterritorialização pelas quais ele foge sem parar. Há ruptura no rizoma cada vez que linhas segmentares explodem numa linha de fuga, mas a linha de fuga faz parte do rizoma (DELEUZE; GUATTARI, 1995, p. 18). 
Fazendo parte do rizoma, essas fugas ou rupturas que o integram agem contingentemente, cristalizam-se momentaneamente apenas para reconfigurar um rizoma em outro, e é nesse sentido que "o bom e o mau são somente o produto de uma seleção ativa e temporária a ser recomeçada" (DELEUZE; GUATTARI, 1995, p. 18). Nossos julgamentos de valor são rizomaticamente construídos a partir de um quadro específico de referência (rizomático ele mesmo): nosso "veredito" contingente sobre determinada situação, portanto, é emitido conforme a situação nos parece mais ou menos próxima desse quadro que tomamos como referência.

O quinto e o sexto princípios do rizoma, também tratados em conjunto, são o da cartografia - ou mapa -, e da decalcomania - ou não decalque, em oposição à lógica da reprodução e do decalque. A ideia aqui é de que mapas não reproduzem realidades, mas as constroem em sua natureza aberta,

conectável em todas as suas dimensōes, desmontável, reversível, suscetível de receber modificações constantemente. Ele pode [...] ser preparado por um indivíduo, um grupo, uma formação social. Podese desenhá-lo numa parede, concebê-lo como obra de arte, construílo como uma ação política ou como uma meditação (DELEUZE; GUATTARI, 1995, p. 22).

Como um rizoma, explicam Deleuze e Guattari, o mapa comporta em si a possibilidade do decalque, ou seja, pode ser fixado em decalque, fechado em mecanismos miméticos, em linhas de fuga, que por sua vez reproduzem as próprias formações que as linhas desfizeram ou inverteram: "é sempre o imitador quem cria seu modelo e o atrai [...] o decalque gerou, estruturalizou o rizoma, e o decalque já não reproduz senão ele mesmo quando crê reproduzir outra coisa. Por isso ele é tão perigoso" (DELEUZE; GUATTARI, 1995, p. 23).

O quadro a seguir, baseado em Deleuze e Guattari (1995), resume as principais diferenças entre o paradigma arbóreo e o rizomático, discutidos neste artigo. 


\section{QUADRO 1}

Quadro comparativo entre a árvore e o rizoma

\begin{tabular}{|l|l|}
\hline \multicolumn{1}{|c|}{ ÁRVORE } & \multicolumn{1}{c|}{ RIZOMA } \\
\hline Estrutura & Sistema \\
\hline Genealogia & Antigenealogia \\
\hline Linearidade & Iimprevisibilidade \\
\hline Hierarquia & Transgressão \\
\hline Ciclos com início, meio e fim & Intermezzo \\
\hline Pivô central & Trama neural, Multiplicidade \\
\hline Continuidade & Ruptura a-significante \\
\hline Reprodução, decalque & Mapas \\
\hline
\end{tabular}

\section{O estudo}

Conforme já descrito, nosso estudo envolveu 18 professores de inglês do Centro de Línguas (CELIN), ligado à UFPR. Os professores participantes serão chamados de $\mathrm{P} 1, \mathrm{P} 2, \mathrm{P} 3$, e assim por diante, para resguardar suas identidades. As representaçóes dos professores a respeito de seu desenvolvimento profissional foram analisadas segundo os campos semânticos implícitos nas partes de uma árvore, a saber: o solo (com quatro ocorrências em 18 desenhos); raízes (18/18); tronco (17/18); galhos e folhas (15/18); flores e frutos (8/18); outros (9/18). Ou seja, nem todos os professores escreveram ou desenharam em todos os campos semânticos analisados. A categoria "outros" inclui desenhos diversos, tais como pássaros voando, uma menina segurando uma escada perto da árvore, formigas subindo no tronco da árvore, um pássaro polinizando flores na copa, coraçōes pendurados como se fossem frutos, um sol, flores no solo ao redor do tronco, borboletas e nuvens no céu, elementos que consideramos externos ao modelo da árvore.

A seguir, apresentamos alguns comentários acerca das partes da árvore e como foram representadas pelos professores. Em seguida, destacaremos, em alguns desenhos, os elementos "destoantes", isto é, aqueles que evidenciam a metáfora da árvore como insuficiente para alguns professores, uma vez que necessitaram incluir outros elementos além dos tipicamente arbóreos para representar seu desenvolvimento profissional.

O solo, conforme representado pelos professores, traz elementos que são, ao mesmo tempo, resultado do desgaste e do declínio da árvore e também da necessidade de reciclar e transformar "o velho" em algo novo. Temos, por 
exemplo, um desenho que traz frutas caídas no chão, com os dizeres "alunos que reprovam; coisas que não dão certo" (P11), ou seja, frustrações com o próprio desenvolvimento. Mas traz também os dizeres "coisas velhas que dão espaço a coisas novas; frutas estragadas que fertilizam o solo e aumentam a experiência" (P11), o que implica renovação e transformação positiva. Em outros dois desenhos, temos as frases "o que me alimenta, honestidade, trabalho duro, etc." (P9) e "responsabilidade e atenção" (P4). O solo seria, ao mesmo tempo, um depósito de frutas em decomposição e de nutrientes que retornam à árvore em forma de alimento.

As raizes parecem ter uma função semelhante à do solo, uma vez que trazem questões relevantes para a base do conhecimento adquirido, embora apenas questôes positivas para o desenvolvimento tenham sido apontadas. Em geral, são valores relacionados a sonhos, sentimentos, desejos, família, amigos e à formação inicial (cursos de línguas, de educação básica, de graduação e pósgraduação, conhecimentos obtidos por meio de leituras, interesses e crenças). P8, por exemplo, cita "formação cultural, social e educacional, leituras, e estudos". P10 é bastante explícito em relação aos elementos que mais influenciaram sua formação ao mencionar "amigos, influência de professores, influência dos pais, jardim de infância, ensino básico, habilidades e objetivos pessoais".

O tronco é visto como a estrutura que dá sustentação, trazendo alguns elementos semelhantes aos das raízes, mas também incluindo a atuação profissional, experiências concretas de formação e de ensino, vivências no exterior e atuação na universidade. $\mathrm{O}$ tronco parece ter um caráter mais prático - experiências de vida do professor e ações que desenvolve em prol de sua formação profissional. Na medida em que vamos subindo nas partes superiores da árvore, surgem mais elementos relacionados à realização profissional, que têm sua origem em valores e na formação inicial. P9 se refere ao tronco como "o que me dá sustentação, minha família, amigos, minhas crenças e o que tenho feito para melhorar a minha vida em geral". P15 menciona "a universidade, o CELIN (como campo de estágio), a graduação e o curso de formação para professores (oferecido pelo CELIN)". Onze dos 18 professores mencionaram explicitamente suas experiências com ensino ou o CELIN (seu local de trabalho e estágio).

Os galhos e folhas parecem estar mais relacionados a sonhos, ambições e projetos futuros, embora também contenham elementos relacionados ao trabalho. P4, por exemplo, menciona "planos, interesses, outros cursos e projetos, realizações, comprometimento e desejos". Já P5 projeta seus planos futuros em termos de estudos e menciona "exame de proficiência da 
Universidade de Cambridge, mestrado e doutorado". P13 traz diversas dúvidas em relação ao seu desenvolvimento, questionando inclusive se está ou não no caminho certo

\author{
Realizações \\ Modificar minhas visões \\ Frustração \\ Buscar saber mais \\ Isto é o que eu quero? (P13)
}

As flores e frutos se parecem um pouco com os galhos efolhas, por estarem relacionadas a sonhos e ambiçôes, mas trazem alguns elementos ligados aos resultados do trabalho (os frutos do trabalho) e a coisas positivas (as flores). P17, por exemplo, desenhou flores e escreveu "surpresas" ao lado delas. P1 1 relacionou os frutos aos resultados de um trabalho árduo e as flores a ideias que compartilha com seus colegas. P9 questiona suas contribuiçōes ao perguntar "o que mais posso oferecer à sociedade?". P7 se refere aos frutos e flores como sua maior aspiração profissional, "o objetivo de me tornar um(a) professor(a) consciente do que significa de fato ensinar".

No campo "outros", conforme dito anteriormente, temos itens que fogem da metáfora da árvore, trazendo elementos que ela parece não contemplar, embora sejam, evidentemente, relacionáveis ao esquema "árvore". P3, por exemplo, desenhou um pássaro carregando uma pequena trouxa no bico (possivelmente levando embora, para longe), com os dizeres "pânico de cometer erros, acomodação com o uso do livro didático, medo por falta de experiência, hesitaçôes". P11 desenhou um pássaro sobrevoando a árvore com os dizeres "polinização, outros professores e alunos", numa alusão de que o processo de desenvolvimento profissional envolve a interação com outros sujeitos que dele fazem parte, reconhecendo, em outras palavras, a presença do "outro". P13 mostrou coraçōes inteiros e partidos como se fossem frutos. P10 incluiu formigas subindo pelo tronco da árvore e carregando pedaços de folhas, que deixam cair ao chegar ao tronco. P7 desenhou uma menina segurando ou subindo numa escada de mão cujo único ponto de sustentação éo solo. O desenho de $\mathrm{P} 17$ mostra também um pássaro de costas, num dos galhos, com a frase "olhar para o passado".

O que a categoria "outros" nos informa é que as ideias mais imediatamente associadas à árvore, como as retratadas nas outras categorias, não parecem suficientes para representar o processo de desenvolvimento do professor, especialmente para aqueles professores que percebem em sua formação um caráter mais "ecológico" e amplo. É assim que fomos levados a constatar, a partir dos desenhos elaborados 
pelos professores, que a metáfora da árvore não dá conta da complexidade do mundo em que vivemos - um mundo que, em sua atual configuração (especialmente com as formas de comunicação possibilitadas pelas novas tecnologias), se torna ainda mais inescapavelmente plural e móvel. Esse mundo nos coloca em posiçôes de sujeito provisórias e variadas, que nos chamam a responsabilidades também diferenciadas. Como explica Souza,

Quando nós seguimos a metáfora linear preestabelecida o nosso papel já foi pré-identificado, nós só temos que seguir o "script" que alguém escreveu pra nós. Quando lidamos com a metáfora do rizoma, da complexidade, da pluralidade, ou seja, da confusão, aí que surge nossa responsabilidade: onde que eu estou? Que confusão é essa? Como que eu vou entender, traduzir esta aparente confusão em algo que faz sentido? E essa interpretação dessa confusão vai ser responsabilidade minha. E como é uma aparente confusão que não tem início, meio nem fim, eu que vou tentar interpretá-la o tempo todo, vou dialogar com essa complexidade o tempo todo, e eu tenho que assumir a responsabilidade por esse diálogo (SOUZA, 2011, p. 282).

A constatação de que vivermos nesse diálogo permanente, cuja responsabilidade temos de assumir, nos leva a uma abertura maior no trabalho com a formação de professores e a ocupar posiçōes de formadores mais flexíveis e receptivas às questões trazidas pelos próprios professores em formação. No caso em estudo, assumir a perspectiva de rizoma nos foi, de certo modo, uma atitude exigida pelo grupo de professores: ao nos fazerem constatar a necessidade de criarmos uma categoria chamada "outros" para abrigar os desenhos que fugiram da estrutura arbórea por nós solicitada, os professores nos lançaram num mundo complexo do qual só se podem estabelecer entendimentos negociados e provisórios.

\section{Considerações finais}

Resumidamente, os elementos que apareceram nas categorias solo, raízes, tronco, galhos e folhas, e flores e frutos remetem claramente ao paradigma da árvore: remetem à ideia de que existe uma base fundamental comum, que alimenta o resto da estrutura - esta seria ramificada, mas sempre

\footnotetext{
${ }^{5}$ Para um entendimento aprofundado do que seja o paradigma ecológico de formação, ver Rogoff (2003).
} 
passando "do Uno a três, quatro ou cinco, mas sempre com a condição de dispor de uma forte unidade principal, a do pivô, que suporta as raízes secundárias" (DELEUZE; GUATTARI, 1995, p. 13). Além disso, os elementos desenhados pelos professores trazem também a noção de linearidade e hierarquização, na medida em se podem identificar as origens e as ramificações com facilidade: no solo e nas raízes, encontramos ideias relacionadas a valores, família, o background afetivo, moral e educacional que serviria de base para o desenvolvimento profissional. A esses elementos, no tronco da árvore, seguem-se aspectos da vivência dos professores tanto em cursos profissionalizantes quanto na prática pedagógica - estágios, trabalho em escolas, etc. Linearmente aparecem, então, como galhos e folhas, flores e frutos, os desdobramentos da experiência profissional: sonhos, ambições e desejos que surgem como consequência do exercício do magistério. Por outro lado, apareceram também elementos que escapam à sistematização e às ideias de "linhagem" ou "descendência”, típicas do paradigma da árvore: esses elementos nos chamaram a atenção para questôes voltadas para a ordem da conectividade, da heterogeneidade, da multiplicidade das representaçôes que os professores fazem de si mesmos e uns dos outros em sua formação.

O exercício proposto aos professores induzia a referência ao paradigma arbóreo como modelo de representação de sua formação, mas, ao tentarem encaixar nesse modelo suas percepções, alguns professores resistiram à imposição de sentidos e escamotearam na árvore (todos os desenhos tinham representações arbóreas) elementos que subvertem o modelo e aparentemente acomodam melhor os sentidos construídos por cada professor. Essas "linhas de fuga” (DELEUZE; GUATTARI, 1995) desestabilizam os sentidos possíveis ao estabelecerem novas possibilidades de relações, diferentes daquelas previstas pelo modelo de árvore - imprevisíveis e, portanto, modificadoras da própria natureza da representação: como afirmam Deleuze e Guattari,

Uma tal multiplicidade não varia suas dimensões sem mudar de natureza nela mesma e se metamorfosear. Oposto a uma estrutura, que se define por um conjunto de pontos e posições, por correlações binárias entre estes pontos e relações biunívocas entre estas posições, o rizoma é feito somente de linhas: linhas de segmentaridade, de estratificação, como dimensões, mas também linha de fuga ou de desterritorialização (DELEUZE; GUATTARI, 1995, p. 32).

Foi assim que essa atividade, de início despretensiosamente em busca de uma conscientização dos professores quanto a seus caminhos formativos, 
oportunizou uma análise mais significativa das representaçôes que eles fazem de sua própria formação. Com a análise, pudemos perceber que as estruturas sistematizadoras do pensamento e da percepção que ainda nos referenciam os sentidos parecem se encontrar no paradigma arbóreo, principalmente na medida em que buscam a discriminação de relações lineares e monológicas de causa e consequência; pudemos perceber, também, que os conceitos de hierarquização e homogeneização estão muito presentes em nossos modos de representar e construir sentidos.

Mas percebemos, acima de tudo, que muitos sentidos fogem a esses modos de representação e precisam de outras metáforas, como a do rizoma, para serem compreendidos e legitimados como sentidos possíveis e produtivos. Sentidos dessa ordem, entretanto, podem não encontrar espaços de representação na coletividade e gerar frustração e ostracismo por parte daqueles que não encontram nos paradigmas institucionais representações de si que considerem adequadas. Isso, na formação de professores, mostra a importância de se considerar outras formas de construir sentidos e representações pessoais e profissionais.

Pensamos que, ao rejeitar ou questionar o paradigma arbóreo (junto com a ideia de ciclos de vida profissional mais ou menos lineares), o professor possa pensar a sua formação como algo que poderia se dar de forma mais permanente, sem início, meio e fim (o intermezzo de Deleuze e Guattari), vislumbrando oportunidades de desenvolvimento mesmo após algumas décadas de trabalho. Nesse sentido, pensamos que a ideia do rizoma na formação continuada contempla a possibilidade de o professor pensar novo, fazer coisas diferentes, sem que antes tenha havido algo que as antecedesse em termos teóricos, sem a necessidade de pensarmos em um pivô que se ramifique e se expanda em alguma direção específica passível de previsão ou controle. Ou seja, não é necessário que haja uma evolução linear, hierárquica e previsível que justifique uma determinada escolha em termos formativos: a formação, um processo de construção identitária, acontece contingencialmente, num movimento de "deriva" que implica um "curso que se produz, momento a momento, nas interações do sistema e suas circunstâncias” (MATURANA, 2001, p. 81).

A formação rizomática pressupõe uma mobilidade "transgressora" (pra usar o termo de Pennycook [2009]) que transpõe a fixidez das disciplinas que fazem parte da formação e modifica todos os elementos que dela participam - movimento que ao mesmo tempo desestabiliza e transforma, em vez de simplesmente se opor ou continuar o que veio antes. 


\section{Referências}

BHABHA, H. K. O local da cultura. Belo Horizonte: Editora UFMG, 1998.

CLIFFORD, J.; MARCUS, G. Writing culture: the poetics and politics of ethnography. Berkeley: University of California Press, 1986.

DELEUZE, G.; GUATTARI, F. Mil Platôs: capitalismo e esquizofrenia. Tradução de Aurélio Guerra Neto e Célia Pinto Costa. São Paulo: Editora 34, 1995.

DINES, A. A metáfora da semente. 2004. Disponível em: <http:// www.observatorio daimprensa.com.br/artigos.asp? $\operatorname{cod}=275 \mathrm{OI} 8005>$. Acesso em: 15 maio 2011.

FEIMAN-NEMSER, S. Staff development and learning to teach. In: ANNUAL MEETING OF THE EASTERN EDUCATIONAL RESEARCH ASSOCIATION, 1982, Detroit. Proceedings... Detroit: AERA, 1982. p. 1-18.

FOLLE, A. et al. Nível de (in)satisfação profissional de professores de Educação Física da Educação Infantil. Motriz, Rio Claro, v. 14, n. 2, p. 124-134, abr./jun. 2008.

JESUS, S. N.; SANTOS, J. C. V. Desenvolvimento profissional e motivação dos professores. Educação, Porto Alegre, v. 27, n. 1, p. 39-58, 2004. Disponível em: $<$ http://revistaseletronicas.pucrs.br/ojs/index.php/faced/article/viewFile/373/ 270>. Acesso em: 15 maio 2007.

HUBERMAN, M. O ciclo de vida profissional dos professores. In: NÓVOA. A. (Org.). Vidas de professores. 2. ed. Porto: Porto Editora, 1995. p. 31- 61.

LA FONTAINE, J. O carvalho e o junco. In: . As mais belas fábulas de La Fontaine. Ilustrações de Gauthier Dosimont. São Paulo: Impala, 1998, p. 16-21. MATURANA, H. Ciência, cognição e vida cotidiana. Belo Horizonte: Editora UFMG, 2001.

PENNYCOOK, A. Uma lingüística aplicada transgressiva. In: MOITA-LOPES, L. P. (Org.). Por uma lingüistica aplicada indisciplinar. São Paulo: Parábola, 2006. ROGOFF, B. The cultural nature of human development. New York: New York University Press. 2003.

SOUZA, L. M. T. M. O professor de inglês e os letramentos no século XXI: métodos ou ética? In: JORDÃO, C. M; MARTINEZ, J. Z.; HALU, R.C. (Org.). Formação (des)formatada: práticas com professores de língua inglesa. São Paulo: Pontes, 2011.

WOODWARD, T. The professional life cycles of teachers. IATEFL Slovenia Newsletter, n. 13, p. 10-11, 2000. 


\section{ANEXO A}

\section{A fábula do carvalho e do junco}

Conversando certo dia disse o carvalho ao junco:

"Você tem bons motivos para reclamar da natureza.

Até um passarinho é um fardo pesado para você."

"Um ventinho à toa que faça

A superfície da água enrugar,

Obriga você a cabeça baixar.

Por outro lado, minha fronte,

Não contente em segurar os raios do sol,

Enfrenta bravamente a tempestade.

Para você tudo é vento violento,

Para mim, brisa suave.

Se você nascesse abrigado pela folhagem

Com que eu cubro a vizinhança,

Não iria sofrer tanto: Eu defenderia você da chuva."

"Mas vocês costumam nascer

Nas bordas úmidas do reino do vento.

A natureza, apesar de tudo,

Com você parece injusta."

- "Sua compaixão", respondeu o arbusto,

"É sincera, eu sei, mas não se inquiete:

Para mim, os ventos não são tão terríveis:

Eu me curvo e não me quebro.

Você tem esse corpo grande

E resiste sem entortar,

Mas espera o fim chegar."

Enquanto diziam essas palavras,

Lá no horizonte furiosamente surgiu

A mais terrível das tempestades

Que os ventos do norte podiam trazer.

A árvore tentou resistir, o junco se curvou.

$\mathrm{O}$ vento redobrou seus esforços.

E tanto fez que destruiu

Aquele que tinha o céu como vizinho de cima

$\mathrm{E}$ as raízes no andar de baixo.

LA FONTAINE, J. O carvalho e o junco. In: - As mais belas fábulas de La Fontaine. Ilustraçôes de Gauthier Dosimont. São Paulo: Impala, 1998, p. 16-21. 


\section{ANEXO B}

\section{Desenho de autoria de P11}

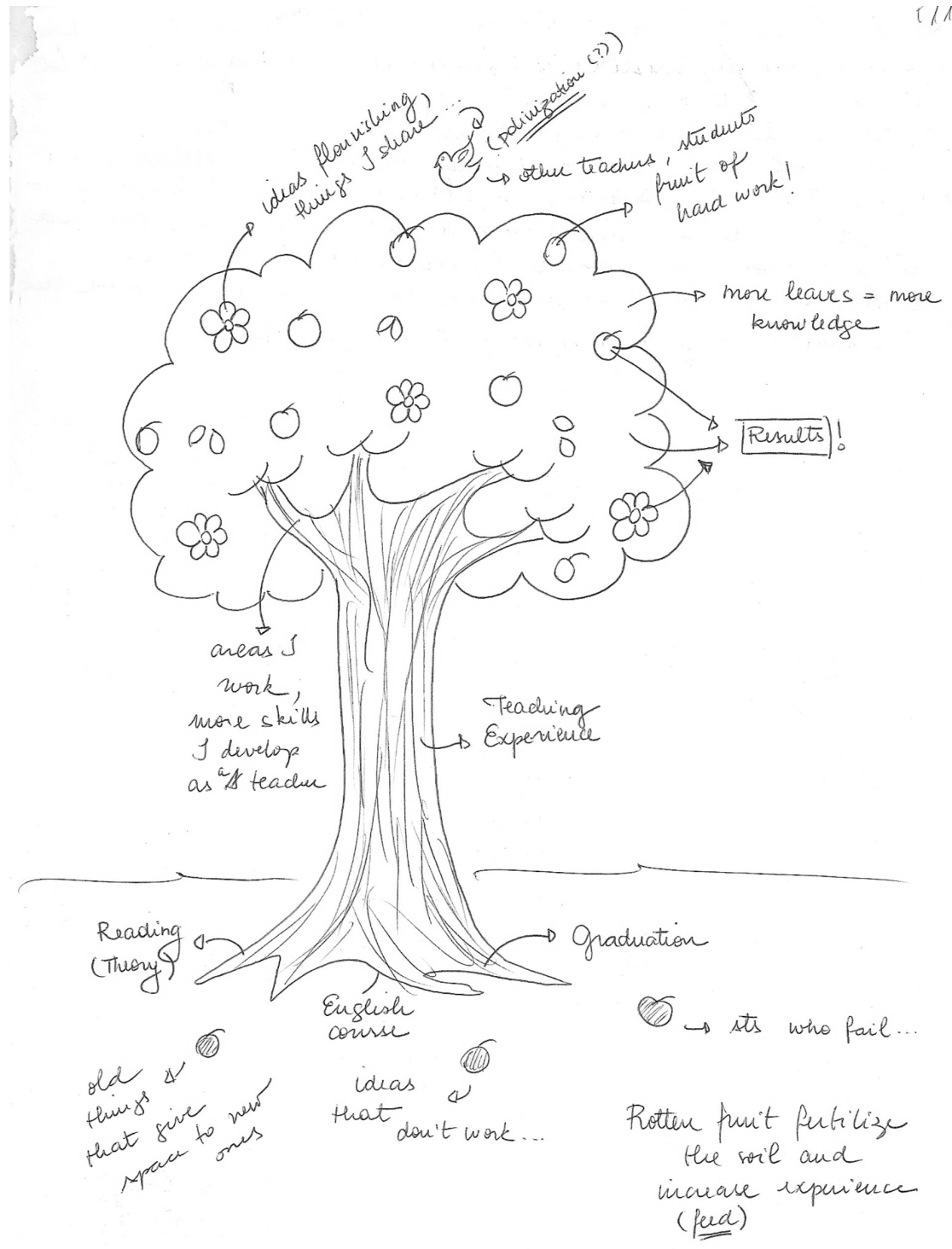

Recebido em 20/10/2011. Aprovado em 12/4/2012. 